\title{
Fan Empathy as a Response to Athlete Transgressions
}

\begin{abstract}
Sport has the capacity to intimately engage fans, deliver intensely emotional experiences, and create attachments to athletes and teams. This connection can be threatened by a number of actions or incidents, including scandals, and fans may engage in a range of behaviors to protect their identification. The purpose of this study is to explore and explicate the concept of fan empathy and illuminate the processes that fans engage in that lead to an empathetic response. Using data from online discussion forums and in-depth interviews, the authors examined empathy in the context of athlete misbehavior and indiscretions. Results provide evidence for the concept of fan empathy as both a cognitive and emotionally focused response, extending the current knowledge of fan behavior. Further, the findings reveal five sensemaking processes that facilitate an empathetic response in the context of inappropriate athlete behavior. This research has implications for sport managers seeking to manage and maintain relationships with fans, including in the face of actions or behavior that might threaten fan identification and association with the sport entity.
\end{abstract}

Key words: fans; empathy; transgressions; athletes; identification. 


\section{Introduction}

The emotional and psychological connection that a fan has with a team or sport object can manifest as an alignment between the fan's values and those of the sport object.

However, a disconnect between these values can create conflict that can threaten fan identity and spur efforts to protect that identity (Hyatt \& Foster, 2015). For example, in the case of athlete misbehavior, some fans may seek to justify their ongoing connection to the team or athlete and protect their identity by employing moral disengagement strategies (Lee, Kwak \& Braunstein-Minkove, 2016). That is, identification can suppress fans' negative moral emotions through cognitive responses such as moral rationalization and moral decoupling, while also enabling them to feel more forgiving and sometimes defend the transgressing party (Lee et al., 2016). Alternatively, fans may engage in biased attributions to reframe the behavior in a more positive light (Wann \& Dolan, 2001), thereby excusing the behavior on the basis of careful contextualization.

In this study, we posit another means by which fans may respond to incidents that conflict with their values and potentially threaten their identification with a sport object: fan empathy. The construct of empathy is "central to the human moral affective system" (Tangey, Stuewig \& Mashek, 2007, p.18) and is of increasing interest to consumer and marketing management researchers because of its "power to predict and explain important social behavior" (Argo, Zhu \& Dahl, 2008, p.615). Empathy has been explored in relation to its influence on consumer response to advertising (Escalas \& Stern, 2003), its role in customer satisfaction with service providers (Weißhaar \& Huber, 2016), how it intensifies reactions to a brand's moral transgression (Romani, Grappi, Zerantonello \& Bagozzi, 2015), and how managerial empathy is used to understand customer needs (Hattula, Herzog, Dahl \& Reineke, 2015). However, empathy has yet to be explored in the context of sport fandom and particularly in relation to athlete misbehavior. The latter is an area of increasing concern to 
sport managers given the increased scrutiny of athletes in the media spotlight, heightened demands from a range of stakeholders, including sponsors, and community expectations that athletes act as role models (Mutter \& Pawlowski, 2014; Smith \& Stewart, 2010).

We demonstrate that empathy is an important, yet under-explored, element of fan behavior, and it can serve as the means by which fans maintain their support when confronted with an athlete transgression. Fan empathy is a particular form of psychological interaction with sport that involves the capacity of a fan to understand and emplace themselves in the lifeworld of the athlete. In doing so, the fan can relate to how the athlete experiences that lifeworld psychologically or emotionally, which in turn may help make sense of the transgression. Empathy flourishes when similarity exists between the self and other, attribution of blame can be shifted to external factors, and perspective-taking is adopted (Pizarro, 2000). As sport and athletes engender high levels of identification through fandom, this in turn creates a conducive environment and network for the expression of empathy.

Athlete transgressions provide a rich context for exploring fan behavior. Transgressions are a violation of the implicit or explicit rules guiding relationship behavior (Aaker, Fournier, \& Brasel, 2004). In recent years many major sports organizations have been challenged by incidents of inappropriate and illegal behavior perpetrated by athletes, along with the subsequent media attention those incidents attract. These transgressions include sexual assault, drug use, driving under the influence of alcohol, speeding, gambling, assault, racist and other discriminatory comments, and on-field violence. The phenomenon of athlete scandals or transgressions has attracted significant researcher interest, particularly in relation to exploring consumer response to these incidents and the implications for athletes, sport managers and sponsors. Previous studies suggest that consumer response can be influenced by a myriad of factors. For example, the nature of the transgression (performance or nonperformance based), perceived intentionality of the act as well as the consumer's 
involvement in sport (Sato, Ko, Park \& Tao, 2015). Consumer response can also be influenced by the reparation efforts of the athlete, for example through improved performance, community service efforts or by issuing an apology (Lee \& Kwak, 2017; Sato et al., 2015). Further, consumer responses may depend on the moral reasoning strategy adopted when processing the transgression (Lee, Kwak \& Moore, 2015).

The concept of fan empathy may provide further insight into some of these findings. For example, empathy or an empathetic response can inform moral judgment (Pizarro, 2000) and therefore could be a precursor to moral reasoning. Further, an antecedent to empathy is attribution of blame, which aligns with the perceived intentionality identified by Sato et al. (2015). As we discuss in the following section, empathy is often associated with an in-group behavior which could explain why consumer response may vary according to level of involvement or identification in sport. Given the heightened level of publicity that athlete transgressions receive, and the potential for damage to the athlete's brand, the sport organization and associated sponsor brands, the concept of fan empathy warrants further investigation.

Drawing on in-depth interviews and online discussion forums, we provide evidence to (a) support the concept of fan empathy, and (b) explicate how fan empathy is experienced and enacted. Towards the first aim, data is presented that establishes fan empathy as both a cognitive and emotional response to an event that has the potential to threaten fan identity. Towards the second aim, we identify five sensemaking processes through which fans make sense of athlete transgressions and engage empathetically: 1) moral testing; 2) weighing the evidence; 3) reserving judgment; 4) recognizing unfair expectations; and 5) explaining a lack of control. These sensemaking processes illuminate the nature and enactment of fan empathy in the context of athlete transgressions. We also propose that these five processes serve as a foundation for further exploration. The results contribute to the literature by identifying and 
defining the concept of fan empathy, including its cognitive and affective attributes, and by demonstrating how sensemaking processes can lead to an empathetic response. The research provides an expanded understanding of how fandom is experienced and how empathy might be used by sport managers to maintain and defend identification. Further, our findings also add to the growing body of research exploring the impact of athlete scandals and transgressions and provide insight to athletes and sport managers as to how to effectively manage these incidents.

\section{Literature review}

\subsection{Empathy}

Empathy is an essential part of all human interaction (Decety \& Lamm, 2006) and represents the "most prototypical human emotion" (Pizarro, 2000, p.355). The English term empathy comes from a direct translation of the German word Einfühlung, meaning 'feeling into' (Singer \& Lamm, 2009). Empathy is a multifaceted construct with both affective and cognitive components and has been described as both a personality trait and a process triggered by a situation specific experience. Regarding this process, deWaal (2008) argues that empathy involves the capacity to share and be affected by the emotional state of another, to assess the reasons for another's state and to identify with the other, adopting his or her perspective. More specifically, Segal (2011, p.267) describes the concept of social empathy as "the insights one has about other people's lives that allow one to understand the circumstances and realities of other people's living situations."

Singer and Lamm (2009) propose that the process of empathy is influenced by at least four factors: the intensity, prominence and valence of the other's display of emotion; the relationship between the empathizer and the other; the personal characteristics of the empathizer (such as age, gender, personality, past experience); and the 'situative' context. It has also been highlighted that context and information are essential to the process of 
empathizing, as it contributes to an individual's ability to engage in perspective-taking (Segal, 2011).

Despite differing views on how to define empathy, Decety and Jackson (2004) claim that there is a general agreement on three components of this multidimensional psychological construct. First, empathy is an affective response to another person and can include emotional concern (Duan \& Hill, 1996). Second, it also involves a cognitive aspect where one adopts or shares the perspective of another, referred to as perspective-taking. Finally, it includes some type of regulatory mechanism that allows one to distinguish between oneself and another. The latter is important in modulating the emotion of the empathetic individual as heightened emotion that leads to a merging of the self and other can lead to negative effects such as confusion, anxiety and depression.

Empathy is a particularly important behavioral element to understand in a variety of contexts and can play a key role in informing moral judgment that is critical to human evaluation and deliberation. Pizarro (2000) notes, when discussing empathy as an emotion capable of rational influence, that such reasoning can act as a "centralizing agent" (p. 358), allowing greater understanding and perspicacity of the issue at hand. This has implications for a range of management situations, particularly where consumers with pre-existing values and relationships need to process events that might, at first, appear to clash with their belief systems. The complexity of empathy makes a nuanced and contextual study especially necessary, given it has been described as an "emotional process" rather than just a discrete emotion (Tangey et al., 2007, p.18).

\subsection{Empathy in marketing}

In the consumer behavior context, empathy constitutes "one's ability to experience and understand another's affective or psychological state" (Argo et al., 2008, p. 615), and an empathic response is "a person's absorption in the feelings of others" (Escalas \& Stern, 2003, 
p. 567). More generally, empathy has been referred to as a response to another person's emotional state (Davis et al., 2017). Empathy has been examined in relation to advertising (e.g., Escalas \& Stern, 2003) and customer interaction with sales and service staff (e.g., Aggarwal, Castleberry, Rignour \& Shepherd, 2005; Weißhaar \& Huber, 2016). Regarding the latter, while most research has focused on the impact of the perceived empathy of service providers on the customer, a recent study has demonstrated that customer empathy with a service provider can increase satisfaction with the service (Davis et al., 2017).

The concept of empathy also has been examined in the marketing management context. Hattula et al. (2015) suggest that managerial empathy is "the mental process of the manager taking the consumers' perspective in order to understand their needs" (p. 236). In this research, focus is placed on perspective-taking as the cognitive component of empathy, based on the rationale that a personal relationship with the consumer does not exist. However, a major criticism is that the literature lacks a multidimensional understanding of empathy in terms of both its cognitive and affective aspects, and how it is experienced by the customer (Weißhaar \& Huber, 2016). In a review of the empathy literature, Misch and Peloquin (2005) conclude that empathy involves both a cognitive and emotional component.

Drawing from the perspectives provided in the social psychology literature and how the construct is examined in the consumer context (Argo et al., 2008), we consider fan empathy as the capacity of a sport fan to experience and understand the athlete's lifeworld in terms of how it contributes to their affective or psychological state. It is useful to explain this definition to make clear its component parts. Fan empathy is about relating to the athlete based on how they experience or account for their lifeworld psychologically or emotionally, for example, in the context of a transgression. Fan empathy incorporates the capacity of the fan to enter into the athlete's lifeworld such that they can experience and understand how it contributes to the athlete's cognitive or emotional state and how this then extends to a 
particular incident or event. The fact that the fan relates by understanding the athlete's lifeworld explains why empathy is often associated with the idea of imagining yourself in the other's shoes (Krebs, 1970). The capacity to experience how the athlete is feeling and thinking (coupled with the fact the fan identifies with the athlete, team or sport) also relates to why the fan processes the incident on a personal level. The fact the definition encompasses the processing of the other's emotional state (in relation to the lifeworld or incident), and that this goes beyond interpreting their cognitive state (consistent with perspective-taking), points to the fact that experiencing empathy has a distinct subjective element.

It is also posited here that fan empathy may be connected to team identification given that empathy is influenced by the type of relationship with 'the other' including the associated attachment (Decety \& Lamm, 2006), and that empathy is seen as in-group phenomena (Eisenberg, 2000). More broadly it stands to reason that identification and empathy are mutually reinforcing in that identification can serve as a catalyst for empathy and empathy may sustain identification (Preston and de Waal, 2002). Though related, it is also made clear in the literature that the concepts of identification and empathy are distinct. Consistent with the previous discussion, and to clarify this distinction, in the next section we draw on the literature to consider how team identification may contribute to an empathetic response, which in turn, may help maintain that identification.

\subsection{Team identification and empathy}

Sport as a form of entertainment can evoke strong emotional involvement due to a sense of personal connectedness (Mael \& Ashforth, 1992; Sutton et al., 1997). In fact, the "extreme emotional intensity" experienced by many fans as a result of their identification with sport, and its competitive nature, differentiates sport from other consumption experiences (King, Kahle, \& Close, 2011, p. 7). An understanding of emotions - and any variables affecting 
them - is important in appreciating the complexity of fan behavior (Kwak et al., 2011) and in providing a more holistic view of fandom (Cottingham, 2012).

Highly identified fans have been found to experience esteem-related benefits as well as increased positive emotions (Delia, 2015; Branscombe \& Wann, 1991). Team identification is defined as "the extent to which a fan feels a psychological connection to the team and the team's performances are viewed as self-relevant" (Wann, 2006, p. 359). Funk and James (2006, p. 206) suggest that allegiance toward a team arises from "placing more functional, emotional, and symbolic meaning on a team based upon a collective set of associations related to escape, success, peer group acceptance, vicarious achievement, nostalgia, and star player."

Identification with social groups more generally is motivated by the desire to achieve positive psychological states and fans may use a variety of strategies to reinforce or even elevate the attractiveness of the group. For example, in the face of a team's poor performance, fans will seek alternative ways to connect that will allow them to maintain their positive identification, focusing on other attractive aspects of group membership and ignoring the negative aspects (Fisher \& Wakefield, 1998). Further, more committed fans exhibit a resistance to negative news coverage and tend to rise to the defense of the team with more favorable assessments (Funk \& Pritchard, 2006). By investigating this increased attachment to sport and associated entities, marketers can begin to understand the "social-structural and individual forces that shape behavior" (Funk \& James, 2006, p. 211).

While team identification is a relatively stable construct, the level of identification may be altered (Wann, 2006). For example, Fink, Parker, Brett and Higgins (2009) found that team identification can be weakened as a result of the improper handling of player scandal by team management. The authors highlight that in the case of an unscrupulous act by an athlete, if the team counter balances this act with a strong response condemning the behavior, the fan 
is provided with something positive to help maintain their identification. Hyatt and Foster (2015) explored a related process they term 'fan de-escalation' whereby the connection between fan and team is severed, finding that one of the key causes is the misalignment of values between the two parties. The authors explore this phenomenon through the lens of identity work theory, suggesting that maintaining identity requires work in the form of particular practices and behaviors that support that identity. Further, if this identity is challenged, fans will "find different cognitive/emotional and practical solutions" (Hyatt \& Foster, 2015, p. 447).

We suggest that, to support their ongoing identity, fans may adopt an empathetic response to situations that could otherwise challenge their team identification. As suggested by deWaal (2008), empathy can be a process triggered by a specific situation and involves the capacity to adopt the other's perspective. Interestingly, empathy has been shown to moderate the intention to engage in 'helping behavior' within a perceived social group, but not between groups (Sturmer, Snyder, Kropp \& Siem, 2006; Zhao et al., 2013). This finding suggests a relationship between group identification and empathy, and that empathy can in turn stimulate a more favorable response to that group.

\section{Method}

While grounded in the context of athlete transgressions, this study centers on exploring the concept of fan empathy. We first identify the elements of fan empathy and then illuminate how fan empathy is enacted; that is, the means or processes by which fans make sense of events that enable them to respond empathetically.

This study began as a broader investigation of fan reactions to athlete transgressions that sought to extend previous work examining sponsor and sporting organization perspectives. The initial analysis of online data, which followed an inductive approach using open, axial and selective coding, revealed a strong theme aligned with the concept of 
empathy as a response to these incidents. This result was somewhat unexpected as previous literature has suggested that sport consumers are becoming increasingly disconnected from elite sport due to several factors including a growing cynicism about the motives of sport actors (Kim \& Trail, 2011). Further, athlete transgressions have been shown to have the potential to negatively impact on levels of team identification (Fink et al., 2009) and to damage relationships with key stakeholders (Westberg, Stavros, \& Wilson, 2011). Conversely, as outlined in the introduction of this article, other studies have indicated that in the case of an athlete's misbehavior, many fans will find a way to justify their ongoing connection to the team or athlete, thus maintaining their identity. As previously stated, there is support in the literature for the concept of fan empathy, but empirical work is needed to provide support for this phenomenon.

Following the initial analysis of an online dataset, additional data were collected using in-depth interviews to further explore fan responses to athlete transgressions and to seek deeper insight into how fans make sense of these events in a way that engenders an empathetic response. Ultimately the study returned to the online dataset to validate the sensemaking processes which emerged from the inductive coding of the interview data while being open to the potential for new processes to emerge. The dataset of online discussions and comments in response to a variety of athlete transgressions, along with the depth interviews, was collected between 2010 and 2015.

With this approach, we acknowledge the insight afforded by the literature noted earlier that demonstrate the characteristics of empathy, including its cognitive and affective elements, its role in personalizing responses to others, and its potential for contributing to the magnitude and character of identification. Although empathy has been explored in other contexts, a comprehensive theoretical framework for its investigation in a sporting context does not exist. As a result, this study did not employ a priori hypotheses for testing against 
data. This analytical approach is therefore interpretive, informed by some nascent understanding about empathy, which framed the research aims. Here, an emerging concept was explored, beginning with a theory-inspired problem and then pursued with a detailed inductive procedure.

\subsection{Research design and collection}

As discussed, the impetus for this research emerged from the analysis of online data to explore more broadly the nature of fan responses to athlete transgressions that had received prominent media attention. In effect, this was the preliminary stage for the current study and it sparked further investigation. This initial data was collected after first identifying incidents of athlete misbehavior and then gathering data from online forums of fans discussing these incidents. Fans on sport-related forums are typically highly-identified as evidenced by the registration process to participate, the number of 'posts' made since joining, and the knowledge and emotional connection demonstrated in their narratives. This level of netnographic inquiry can proffer different perspectives and insights than are available through questioning (Kozinets, 2010), and helped guide the purposive sampling utilized for the next stage of data collection.

The population for the preliminary study was drawn by cataloguing media-reported allegations of athlete misbehavior (irrespective of outcomes or penalties) over several years in two of Australia's leading team sport competitions - the National Rugby League (NRL) and the Australian Football League (AFL). This catalog captured 79 incidents ranging from public urination through to assault. From these, 30 incidences of athlete transgressions that had been widely discussed and were representative of the nature of incidents were more deeply explored resulting in the collection of 9,599 associated fan posts from 11 different outlets. These outlets comprised the most popular sites (by volume of posts) for discussion of these matters and included a mix of specialist sport sites covering the AFL and NRL 
respectively ( 2 sites), leading general sport forums ( 2 sites) and the major metropolitan news sites (7 sites). The incidents considered ranged from illegal gambling ( 1 observation), drink driving (4 observations), inappropriate behavior (4 observations) typically around posts on social media, assault (10 observations) ranging from 'nightclub brawls' to alleged attacks on partners, and drunken behavior (11 observations) which is how the media generally reported a range of catch-all transgressive behaviors that involved anything from creating a public nuisance property damage, excessive noise, public urination and failing to pay taxi fares. This selection was based, aside from the obvious need for commentary, on the following: (a) the incident was discussed by fans in a variety of outlets, and (b) it was viewed as somewhat emblematic of the typical range of transgressive behaviors observed (i.e., at least one of everything in the catalog was considered).

While most comments simply discussed the incident, its repercussions and handling, many comments also revealed both an emotional and cognitive response that in some instances suggested an empathetic response to the athlete's situation. In order to explore the nature of these responses in further detail, in-depth interviews were conducted with purposively sampled informants. The initial data and analysis of online forums provided a structure for the interviews and informed the interview guide, which subsequently evolved as points of focus emerged (Charmaz, 2014). The online data helped inform the interviews in three key areas, beyond the illumination of empathy. First it highlighted a multiple stage approach to transgression response that consisted of the transgression itself and subsequently the reporting the transgression by the actors involved. Second it brought forward contextual elements or points of focus that could be explored in the interviews, including attribution of blame when considering responsibility for transgressions and the individual persona of the athlete and the impact of athletes' backgrounds as an explanation or justification for their actions. Thirdly, it captured the tension with regard the 'role' of an athlete in very clear 
terms, allowing it to become a central tenet to the interviews, with the concept of 'rolemodels' and associated pressures a key prompt for the researcher to explore.

The interviews were conducted with 15 sport fans, eight females and seven males, as detailed at Table 1. Informants' age range was 28 to 50 and interviews were conducted faceto-face by a single researcher. The informants were recruited through a marketing consultancy. The consultancy was briefed to recruit informants with a specific interest in the AFL and/or NRL, given the initial online investigations, as well as a broader interest in sport which ultimately manifested in enthusiasm across a range of sports, including golf, soccer and cycling.

A semi-structured interview protocol was used, with informants free to express their thoughts across a wide-range of contemporary sporting issues, including athlete transgressions. The concept of empathy was not explained, or highlighted in any direct fashion, during the discussion. Instead, informants were asked to comment on the current state of sport, their interest, favored sports and perceptions of modern athletes as a form of rapport building. The discussion was then steered toward athlete misbehavior and viewpoints were encouraged through probing and prompting for examples. While specific transgressions were not introduced by the researcher, each informant was encouraged to present several examples, and these were explored. Given the complex nature of the phenomenon being examined, it was felt that it was more valuable to observe these contextual manifestations of empathy if they arose and if so, how and with what caveats or construction, rather than by forcing issues and removing them from their psycho-social elements. Similarly, the focus was on instances where empathy was demonstrated as a response to a transgression that was noted, rather than where it was not evident. Interviews lasted between 45-60 minutes and were recorded and transcribed, producing 252 pages of single-spaced textual data (approximately 110,000 words). 


\subsection{Data analysis}

Data from online discussion forums was initially coded independently by two researchers who sought to illuminate insights on transgressions more broadly. An initial open stage of coding involved breaking down and examining the data, where it was apparent, for example, that online responses to a transgression and the subsequent handling of the transgression constituted different nodes of discovery. Once particular phenomena had been identified in the data, (e.g., our data indicated numerous areas at this point - expectation of role, perceived transgression, perceived impact/effect, individual persona, attribution of blame, past history and response to transgression) concepts were grouped around them in axial coding before being categorized through selective themes. In this case, relevant to the purpose of this article, theoretical sensitivity was used to carefully process the data. Strauss and Corbin (1990, p. 44) describe theoretical sensitivity as the ability to recognize important elements in the data while giving it meaning, including to "stimulate reflection about the data at hand" (Corbin, 1998, p. 122).

One important outcome of this inductive process was the identification of seemingly empathetic responses in sport fans and this analysis suggested both cognitive and emotional responses to incidents were occurring. This preliminary outcome was not quantified as a proportion of online comments given the varying nature of responses and the selective nature of the transgressions investigated, however it was noted as being particularly intriguing, stimulating reflection and worthy of further investigation at that juncture through further data collection in the form of interviews. As previously noted, the online data, beyond the identification of empathy, helped shape the in-depth interview process.

Two researchers, after reading through the subsequent interview transcripts, met to develop a coding structure to facilitate consistency and rigor. A third researcher examined the clarity of, and points of distinction between, key themes. Text was transferred into a 
spreadsheet to allow for an initial open-coding approach that concentrated on first identifying broad expressions of emotion, processing or response, and was followed by another axial coding pass that sought to put some context to these elements. The axial stage worked to disaggregate the data and locate appropriate linkages and relationships to the broad themes first extracted. This stage deconstructed how informants understood the circumstances (e.g. athlete age, levels of expectation) surrounding and affecting transgressions, in so doing providing rich and valuable manifestations and characteristics of empathy. Insights from axial coding demonstrated and illuminated the pathways to identification behavior.

During these stages, we convened regularly to cross-check the coding process and to discuss any discrepancies. This led to several characteristics being combined, eliminated or re-developed and to ensure applicability to the research aims (Corbin \& Strauss, 2008). Data credibility was reinforced through investigator triangulation given that the researchers concomitantly undertook the coding process, further augmented by peer debriefing where working codes were scrutinized by external parties.

The online comments were subsequently returned to as part of a final deductive process, helping to provide insight concerning differing empathetic characteristics and the interrelated emotional and cognitive responses to athlete transgressions. While the interview data initially yielded processes that fans engage in to make sense of situations that can challenge their connection to a sport object, by returning with these themes to the online data we were able to further exemplify behaviors and reinforce perspectives. In particular, the interactive nature of the asynchronous posting process yielded fresh dimensions that were unavailable during interview settings, such as fans defending athletes from the perceived attacks of others, and in doing so, demonstrating empathy.

\section{Results}


The online and interview data provide evidence for the concept of fan empathy in that fans use their knowledge and experience to adopt the perspective of the athlete, including their emotional state, in response to an athlete transgression. Further, the data reveal sensemaking processes enacted by fans that can facilitate an empathetic response to the athlete or team's circumstances. Collectively, these results provide support for the concept of fan empathy as a psychological and experiential phenomenon in the sport context.

The results will be presented as follows: first, fan responses to athlete transgressions are discussed and evidence is presented to support the concept of fan empathy. More particularly, this discussion elucidates how fan empathy manifests as a sport fan's assessment of elements of the athlete's lifeworld and specifically how that impacts them cognitively and emotionally in the context of a transgression. Second, the processes that fans engage in that underpin an empathetic response to a transgression, and related incidents and influences, are presented. These five processes are described as: moral testing, weighing the evidence, reserving judgment, recognizing unfair expectations and explaining a lack of control. The following sections discuss these results in detail, supported by illustrative informant quotes or online comments. Further, it should be noted that we recognize and account for the fact that while the emotional and cognitive aspects of empathy are explained separately, experientially they are dynamically interrelated. That is, considering the cognitive perspective of another can prompt consideration of their emotional state, and imagining their emotional state or what contributes to it can promote reflection on how they try to make sense of the world (Gerdes \& Segal, 2011). In fact, consistent with our data, we suspect that the intertwined and reinforcing nature of emotional and cognitive empathic processing is a feature of the highly identified fan's response to a transgression. And while it is not a point of focus in our research, it is relevant to note that empathy, based on this consideration of the athlete's cognitive and 
emotional state and related lifeworld factors, has various associated effects for the fan such as experiencing a sense of connectedness or feeling justified in maintaining that connection.

\subsection{Fan responses to athlete transgressions}

In discussing the issue of athlete transgressions, informant accounts often conveyed a strong connection to sport, but critically, also communicated an understanding of the world of the elite sportsperson to illustrate what they are confronted with from an emotional and cognitive perspective.

An empathetic understanding in the context of a transgression manifests as a distinct way of relating to the athlete's emotions and is typically related to the challenges they must contend with, especially in instances where the athlete may not be able to deal with their emotions or these challenges. Many informants demonstrated a considered view of an athlete's circumstances and sometimes offered quite detailed accounts of their lifeworld in an effort to draw out what the athlete might be thinking or feeling, and how this might account for a particular incident. This both heightened their sensitivity to the transgression and helped them to explain it. Experiencing empathy as a result of the ability to recognize what is unique to a person's lifeworld has been discussed in the literature (e.g. Ashworth \& Lucas, 2000).

As previously noted, fan empathy represents the capacity of a sport fan to experience and understand the athlete's lifeworld and how this contributes to their affective or psychological state. As will be presented in the following sections, our data and interpretations demonstrate the ability of sport fans to relate to the athlete's lifeworld and the challenges they face to explain what they contend with emotionally and cognitively, and to use this as a basis to explain their actions, particularly in the context of a transgression.

\subsection{Components of fan empathy}

We identify two interrelated components of fan empathy, namely the ability to relate emotionally and cognitively based on an appreciation of particular aspects of the athlete's 
lifeworld. We use the terms 'relating emotionally' and 'relating cognitively' to capture the fact that the athlete's emotional or cognitive state, including how they feel or make sense of things in the context of their lifeworld, forms the basis on which fans make their connection to the athlete and respond to the transgression or incident.

\subsubsection{Relating emotionally}

Sport consumption by its nature stimulates a high degree of emotion, especially amongst highly identified fans, and this can engender strong attachment to both the sport and individual athletes. Critically, while this attachment and emotion is relevant to what was observed in this study, it became clear that empathy is unique as a form of fan interaction in that it involves understanding what the athlete must deal with on an emotional level including the pressures in their lifeworld, and how this can contribute to athlete misbehavior. Two passages highlight an understanding of the emotional strain faced by athletes:

if $i$ was an afl [Australian Football League] player $i$ wouldn't even leave my house except for training and games. Everyone trying to make a buck off of you, I don't envy them. (participant, online forum)

...there's just so much scrutiny and everyone's got a phone with a camera and, I don't know. I feel sorry because they can't go anywhere ... there's no privacy anywhere for athletes anymore so I think that puts pressure on them. (Mark, 50 years old)

Fans like Mark and others pointed to emotional stresses athletes would be exposed to, such as feeling trapped, exploited or judged and explained the causes, including the fact that athletes have little privacy or opportunity to be themselves, are continually photographed, watched or talked about on social media, and how they would feel concerned that people were constantly seeking to gain something from them. They also spoke of a range of factors 
that contribute to the stress that athletes deal with, including clubs, fellow players, commentators, supporters, the public at large and the media, and of how the intrusiveness was omnipresent, which helped explain why athletes sometimes acted inappropriately. Phrases such as 'feel sorry' or 'feel sad' were frequently used to indicate the difficult aspects of the athlete's lifeworld and their incapacity to cope with them. For example:

I feel sorry for the pro athlete... We have unrealistic expectations of people in the public eye in general and specifically pro athletes. I reckon it's an issue because they're not ... their background... well they didn't get there because they were great role models and they were fantastic with the media, they got there because they could play football and a lot of them don't have a great education or didn't over-perform at school. (Daniel, 30)

Narratives like Daniel's were consistent with the sentiments and sensemaking expressed more generally in terms of how fans imagined the athlete's circumstances and the difficulties they faced in contending with, in this case, highly unrealistic and demanding expectations (such as the need to be role models) and the fact athletes did not always have the wherewithal to deal with them, which compounded the problem. Further highlighting how the fan connected to what the athlete experienced emotionally, informants also indicated that athletes had the right to feel aggrieved not just because of these expectations and pressures, or because they were not equipped or sufficiently supported to deal with them, but because they did not seek to become a role model. Similarly, others like Jessica explained how athletes not only had to deal with the high expectations of performing well on and off the field but also with the media focused on the negative or salacious aspects of an athlete's story.

You don't, you never really hear the, all the facts. Like [name]. Like how did he get into it? Was it when he was playing footy? Was he injured, and he started on you know, drugs to help him with an injury and it just got worse from there? You 
don't know. Or did he just get caught up in the wrong crowd and that's how it started? You know, we never hear about things like that. (Jessica, 37)

The expectations and how they could damage the athlete's life were discussed repeatedly, in different contexts, and on a range of levels. For example, in relation to an ongoing battle with drug addiction faced by a well-known athlete, one informant indicated how these expectations extended to the fact that professional athletes must make the most of their lives given their social contacts, recognition and income. This also greatly added to the perceived emotional downfall that the athlete would experience because feelings of lost opportunity would amplify the sense of loss, shame, guilt or helplessness. Kim commented that she has "a lot of empathy about the drug addictions" in sport because the professional athlete had more to lose.

To see someone so famous and to have everything positive going in their lives and a severe addiction...I am very sad that a person, you know, obviously a person has fallen that far down and has... that addiction. I find that really sad (Kim, 45).

The fact that our informants were adept at articulating various aspects of the athlete's lifeworld and how that could impact them emotionally or cognitively meant they could more fully relate to the athlete's circumstances and the implications of a transgression. This also pointed to a broader insight that emerged from our data. Because many of our informants were highly identified fans and had a strong connection either with the sport, team or athlete, they were better able and seemingly more inclined to imagine the athlete's lifeworld on an emotional level. Kim also spoke about the fact she had a family member whose life was destroyed through drug use. 


\title{
4.2.2 Relating cognitively
}

In addition to understanding what the challenging aspects of the athlete's lifeworld meant for them emotionally, our data demonstrated fans' responding empathetically based on their understanding of the athlete's capacity or efforts to comprehend the environment they found themselves in. As touched on in Daniel's passage when he speaks of professional athletes not being well educated, sufficiently trained, or capable of dealing with the media or societal expectations, others, such as David, also recognized that athletes were not able to fully grasp the life and demands of the professional athlete.

\author{
Some of them [football players] have fairly difficult backgrounds, I'm thinking of \\ things like rugby league for example, they're often from fairly working class \\ backgrounds and then the culture, that culture that they're exposed to, taking \\ blokes as an example, the very tribalistic culture that they're exposed to can put \\ them in a cocoon of what is socially acceptable and morals and social norms that \\ is different or out of skew with society so they probably need that additional \\ training to offset that and provide some balance to that which is really a false \\ reality that they're in. (David, 33)
}

The preceding comments by David are indicative of our data more broadly in the way he constructs and personally connects to an understanding of the athlete's capacity to make sense of what constitutes appropriate behavior; in this case, based on what he and others described as the 'cocoon' that encircles the professional athlete. Many of our informants considered professional athletes as lacking the cognitive capacity to understand the unique pressures and normative expectations to which they were subjected. This was attributed to the fact that athletes are socialized in a subculture with different values or standards from wider society or are too removed from mainstream societal values and norms. Further, this could be 
compounded if an athlete had come from a lower socio-economic status or had limited education prior to entering the world of professional sports.

More broadly, as we came to understand how informants constructed their understanding of incidents, and the lifeworld and certain identity attributes of professional athletes, it became apparent that they engaged in a range of sensemaking processes as part of empathizing with 'the other'. The following section discusses five sensemaking processes that emerged from our data during the process of open and axial coding, as described in the method section. The data suggest that these processes contribute to an empathetic response in the context of an athlete transgression.

\subsection{Fan empathy and sensemaking}

The literature highlights that a powerful way to explore empathy is to consider how the observer takes a position on the 'empathy object' or its component parts, which in this case relates to athlete, lifeworld and incident (Breithaupt, 2012). Our results reveal that fans have different modes of processing an incident consistent with their efforts to internalize key aspects of the athlete's lifeworld. As previously discussed, empathy encompasses both an affective and cognitive element. The affective or emotional component may occur implicitly when internalizing the other and associated circumstances or incidents (Duan \& Hill, 1996), but the cognitive element, understanding how the other makes sense of things, may require more explicit processing (Decety \& Jackson, 2004). We noted five different processes used by our informants, where an understanding of the lifeworld of the athlete was constructed in particular ways to make sense of their behavior (with respect to transgressions). While these sensemaking approaches differ, each enables the fan to relate to the athlete emotionally or cognitively based on how key aspects of their lifeworld factor into their behavior. While the following sections discuss these as discrete processes that facilitate fan empathy, in practice they may manifest in combination as layers of explanation. 


\subsubsection{Moral testing}

We noted that some fans felt compelled to assess the morality of the transgression, both within the context of the athlete's lifeworld, but also outside the sport context, as a basis to understand the athlete's emotional or psychological state. For example, this process could take the form of self-comparison whereby the fan assesses the behavior against how they would be likely to respond. Or, by undertaking various external comparisons such as considering what might be expected of an employee in another business context, or appropriate behavior for other men or women of a similar age or, more broadly, in terms of the general population. For example, in considering an appropriate course of action for an athlete exposed as having a gambling addiction, the following assessment was made:

I think it should parallel with what would happen in the corporate world if an individual.. if it was known to an organization that an individual was a gambling addict, support would be offered initially, but they would have to be committed to putting mechanisms in place to correct their behaviour and be seen to be really proactive and wanting to change. (David, 33)

In this form of sensemaking, fans seek to establish whether the behavior is representative of a moral or normative standard in other contexts in order to make sense of the athlete's current situation and how it should be handled. In David's case, his expectations of both the handling of the transgression and the expectation of the athlete's response are informed by his knowledge in a non-sport context. He frames the transgression as a 'clinical problem' and reiterates the need for the athlete to be supported.

This comparative approach is also evident in the following comment in response to an F1 driver who was accused of dangerous driving on a public road - portrayed as joyriding along a deserted stretch of a major road in the early hours of the morning. The informant contemplated how she might act in the same situation, commenting: 
I personally thought gosh if I had a nice big fast car too, I'd like to maybe take it

a bit faster than normal, so, I don't know... (Sylvia, 39)

This comment highlights an understanding of the temptation that the elite driver might experience and, without condoning the behavior, Sylvia downplays the severity of the incident as she can see herself being tempted in the same way. Similarly, when another informant reflected on golfer Tiger Woods' alleged adultery, he drew upon his own experience, stating:

I reckon in Tiger's case, I know just as many blokes who would say 'the lucky bastard good luck to him', probably more blokes are gonna say that, and probably more females say you know, 'the dirty rotten scoundrel'. At the end of the day it is what it is and jeez, you know, who am I to criticize Tiger I wasn't exactly faithful to my first wife... (Ian, 50).

Several informants commented on Wood's case, or similar high-profile transgressions, and tried to bring some perspective to the incident by acknowledging that he would not be condemned by many males in society as they (like he) had been unfaithful to their partners or had been tempted to do so. Significantly, this incident also had informants imagining the factors that might contribute to this situation from the perspective of athletes such as spending extended time away from their family or frequently being approached by adoring female fans.

\subsubsection{Weighing the evidence}

This process involves the sport fan weighing up the evidence against their knowledge of the athlete, team or other relevant factors. In the context of a transgression, the fan attempts to make a holistic assessment considering both the negative incident and positive attributes associated with the player, such as their reputation, work in the community, performance on the field, or whether they seem to be good person overall, as a way of more fully 
understanding an athlete's affective or psychological state and how this might help explain the event. We noted several instances where the fan's knowledge of the athlete and their character, played a key role in how the transgression was perceived. Or, they simply consider whether the evidence at hand is credible. In reference to a cricket player who had been in the media for various minor indiscretions, one informant commented:

...he's a fantastic bloke, fantastic guy, so that kind of, that would, that kind of colours my view of [the player] a little bit. (Sam, 36)

Similarly, in discussing an incident pertaining to a football player who allegedly had been evicted from a bar for brawling, many of the participants in an online discussion forum felt that it was unlikely that the player had instigated the incident given his reputation: ...[player name] always seems like a relaxed, down to earth guy, so I doubt he would ever assault someone without being provoked, but as usual [newspaper name] only prints half the story (and of course, the half is damning a well known football player.) (online forum participant)

The insight of fans into the lifeworld of the athlete, including the role of the media, meant that they understood the challenges sometimes faced by athletes in terms of unwanted attention. In making sense of a transgression, particularly in relation to altercations in public places such as bars, fans often weighed-up the details of the incident against their knowledge of the athlete or their lifeworld, such as how athletes, because of their position, can inadvertently attract trouble from those looking to show off their masculinity. Several online forum participants acknowledged this phenomenon and the role it can play in these incidents, as indicated in the following comments:

It's amazing and worrying how many scumbags there are out there who think they're a hero if they hit an AFL player. 'No you giant spanner it does not make you a hero', you hit a bloke unawares because he has made more of his life than 
you, all it does is confirm that you are a twit. Smells of sour grapes to me. (online forum participant)

AFL stars have to watch out big time. There is always someone willing to try and go down in local history. (online forum participant)

Weighing the evidence could also involve downplaying or dismissing the negative ('it really isn't anyone's business') or accentuating the positive. This latter sentiment is illustrated by the following reaction in relation to a high-profile football player who had been caught driving with a blood alcohol level slightly over the legally acceptable limit. Many fans expressed surprise at the behavior based on their understanding of the player's character, ability and actions both on and off the field, leading to a broadly held view that it was out of character. The following comment on an online sport forum demonstrates how a fan might acknowledge the validity of the transgression but weigh it up against the more positive beliefs and knowledge about the athlete held by the fan:

So, [player name] made a mistake. Listen you doubters out there, he's the best captain we've ever had, fearless, supportive, brilliant footballer and a great leader on and off the field. One of the smartest footballers who ever played the game. And he's been a great player in big games: 2 [major awards] says it all. Anyone "losing respect" for [player nickname] can just $f^{* * *}$ off. (participant, online forum)

Fans like this online participant would seek to find positive aspects of the player including those reflected in their lives off the field to counteract the negative aspects of the transgression. Not surprisingly, fans like this online participant also demonstrated high levels of identification with certain athletes, and this was also significant as this enabled them to establish the character of the player (sometimes in comprehensive ways) as a basis for weighing up the evidence and to determine that the transgression was an uncharacteristic 
mistake or that the athlete was being treated unfairly. In some cases, as indicated in the preceding comment, this conclusion helped to justify the fan's unconditional support. This example of the 'weighing the evidence' sensemaking process is also consistent with a resistance strategy used to reject attempts to persuade, in this case the criticism of an admired player. This fan's response shares characteristics of attitude bolstering whereby an individual conjures thoughts that are consistent with their existing attitude without necessarily refuting the persuasive message (Zuwerink, Jacks \& Cameron, 2003). In this example, the fan accepts that the transgression has occurred but is resolute in suggesting that it is outweighed by the athlete's positive attributes.

\subsubsection{Reserving judgment}

This process involves the fan holding back judgment after initial awareness of the incident. As one informant expressed, "there's a reason for everything, and it's not always black and white." Critically this form of sensemaking was often predicated on the fact that the athlete's lifeworld was somehow compromised or intruded upon, or made especially difficult in some way, because of the relentless public attention and the fact that the media were prone to sensationalism or intrusion ("media stick their nose too far into AFL players' private lives").

As a result, some fans wanted more information to better understand the cause of the incident prior to making a judgment, as illustrated in the following passage:

I guess I sort of always try to think about it from an objective point of view, and just all I know about you is this sort of thing, I don't know what caused it, I don't know the specifics around it, and I'm not saying that necessarily there's always an explanation as to why someone would've done something one way or another, but you're like, like I'm not going to make an opinion about you, because I don't have enough information. (Sean, 28) 
In this process of sensemaking there often was recognition of the complexity or questionable nature of an incident to explain why a judgment would not be made. Further, the inclination to reserve judgment often resulted in giving the athlete the "benefit of the doubt."

A number of our informants commented on the questionable role of the media in reporting these incidents, which would not occur in the case of an average person, and also the credibility of what was reported. For example, Mark expressed his reluctance to make a judgement regarding the reporting of a couple of athletes who had been caught driving while intoxicated:

...the ones that we get in the press are mainly football drink driving type of things or football indiscretions, but you just wonder if we've really got the full story on something too. I'm always a little bit, what's the word... suspicious of whether we've got the full facts of a situation, if there's not a distortion on the reporting sometimes. (Mark, 50)

Understanding the difficult nature of athletes' lives meant that some fans wanted to wait for the facts to emerge or hold judgement until they could assess additional information to ascertain a more complete or truer picture of the situation. One informant described how she would get more background information on high profile incidents to better understand any alleged behavior and to allow her to communicate the 'full' story to her children: ... if you don't get the whole story, you know, if you miss bits of it, you will try and get the next lot of news and catch up on it. Or if the kids see it you sort of try to find out what you can, you know, Google it. You know, so then if the kids want to know you can let them know what's happened. ... Like there might be bits in the story that, you know, why it's happened. There might be a background to why it's happened. (Natalie, 43) 
Like others, Natalie was wary of what she perceived as the dubious motives of the media, which would often only present 'half the facts' to sensationalize an incident.

\subsubsection{Recognizing unfair expectations}

This process is related somewhat to Moral Testing in that the sport fan undertakes a form of comparative analysis. However, as opposed to comparing the athlete's behavior to oneself or other members of the non-sport community, this process relates to assessing the behavior against expected behavior for an athlete. It is a process by which the fan evaluates what is to be expected given the unique context in which the athlete operates; that is, the highly pressurized environment of professional sport. To engage in this form of sensemaking, the fan needs a deep insight into what it means to be a professional athlete. The following passage indicates how the lifeworld of the players, including unrealistic or unfair expectations of other parties such as sport clubs and the media, influences their cognitive and emotional state and consequently, the transgression.

The media has put them in a position where we should be [unfairly] holding them much more responsible for those things because they're a role model. Now I reckon that's unfair and unrealistic and the people that have decided that they're role models, and actually put them up as role models, which are the clubs, the associations you know the FFA, AFL, all those things, so they've put their [brand] behind them and said you have to be a role model so whether those guys have agreed to it or not, if you're not contractually bound to do it, don't hold them like it's a contract. If it has a direct impact on their ability to play cool, the clubs have something to do about that and they should have something to say about that, but the rest, you know, and it shouldn't be aired. For God's sake stop putting it in the bloody media! (Daniel, 30) 
In the preceding comment, Daniel clearly articulates his understanding of how athletes are forced to adopt certain roles, pronouncing this as 'unfair' and 'unrealistic'. Further, blame for this situation is apportioned to both the media and sport club.

In terms of the expectations of a professional athlete, there was prolonged discussion by several informants as to whether professional athletes are, or should be, role models. It has been noted that people are increasingly turning to the world of sport for their heroes and role models (Parry, 2009; Rojek, 2006). Those informants who did not put athletes on a pedestal as role models had more modest expectations of athlete behavior and demonstrated more empathy in relation to off-field transgressions, particularly those that were relatively less severe. This viewpoint is illustrated in the following comments:

Well look again, these people they're just human beings they're representative of you know people just out in society and they're probably, we probably think they should be less fallible than most but in actual fact they're not. They're just the same as everyone else. (Ian, 50)

I don't know, maybe because they're such good athletes, because they're so good at their sport, we think they're going to be so good in their personal life. I think we just expect them to have that control, both personally and professionally. (Bernadette, 37)

\subsubsection{Explaining a lack of control}

This process involves the fan seeking to identify potential causes or explanations for the behavior to shift the locus of control away from the athlete. Some fans felt that there were numerous factors outside the athlete's control that explained why an incident occurred. These factors could be psychological, for example an athlete's addiction, attention deficit disorder, or inability to handle pressure, or external, for example a difficult upbringing, unfair media 
scrutiny or biased reporting, or even more broadly, the unrelenting or societally-removed culture of sport.

The following comment relates to a media report whereby a football player was alleged to have assaulted his partner and was posted as part of a lengthy discussion about the incident on a sport forum:

Unfortunately, what [athlete name] did is a result of the environment he was brought up in. The abuse of women is something he would have seen on a daily basis whilst growing up in [name of small town]. I have been there a few times, and the mission looks like it has had a bomb dropped on it. Drugs and alcohol are huge problems. This cannot be held as an excuse for his actions. He has been given an opportunity in life that not many get. Unfortunately like a lot of people, the bottle can bring out their demons and they often resort back to their bad ways when they start drinking in excess. This is a society problem and not a league problem (participant, online forum).

As illustrated by this post, the forum participant draws attention to elements that contribute to the athlete's inability to control the situation by drawing on his disadvantaged upbringing. While not offered as an excuse, this explanation recognizes that the negative influence of the athlete's roots on aspects of his adult life could be overwhelming. Similarly, informants were able to articulate a range of challenges faced by an athlete that they could not control and the potential pressures that may result. For example, in discussing her response to athlete transgressions in general, one informant reflects on possible reasons for an incident:

Yeah - like I'd always think too what were they doing at the time, like there is usually a reason for why they were doing something like that - whether it was because they were in a group they were egging each other on or they might be 
depressed - like there's always sort of a trigger, like gambling often there's ... obviously can be linked mental health stuff and I always kind of want to know the reason why. (Bianca, 35)

When discussing a prominent AFL player whose serious drug addiction had received extensive media coverage, another informant commented:

"He's obviously a guy in his prime but found drugs, and he probably could've gone on to have, you know, it's just him being probably a young guy with lots of money and not having the right direction, but that can happen to anyone though, you hang out with the wrong people, or you make the wrong choice." (Sylvia, 39)

The preceding quote demonstrates Sylvia's effort to explain the athlete's addiction, proposing potential causes such as youthfulness, 'lots of money', lack of education or limited guidance, and spending time 'with the wrong people' to downplay the athlete's ability to control the situation. Another informant considers external factors such as the potential for peers to be a negative influence:

I think at the end of the day they [athletes] are still human and ... you know, they are going to, they will be pressured into doing things that they are not supposed to. You know, from their peers and other people around them. (Lydia, 33)

Daniel also contemplated the plight of young athletes trying to adjust to the duality of success in professional sport, that is, the celebrity status that brings financial rewards, but also unwanted attention and resulting lifestyle changes:

You're giving 19, 20, 21, 22, 23 year old kids hundreds of thousands of dollars for playing sports and then you're going out and saying but you can't have any fun and you can't do anything with it because as soon as you actually go out and have a beer some smart ass at a pub decides that he's going to have a go at you about something, you can't do anything. (Daniel, 30) 


\section{Discussion and implications}

Our results contribute to a more nuanced understanding of fan behavior by introducing the concept of fan empathy and identifying the sensemaking processes that contribute to this response in the context of athlete transgressions. Fan empathy is the capacity of a sport fan to experience and understand the athlete's lifeworld in terms of how it contributes to their affective or psychological state. Understanding fan empathy adds to our knowledge of how fans experience fandom and illuminates how the perspective of the fan is connected to an understanding of the experiences faced by athletes. We propose that fan empathy may be connected to team identification given that the broader literature suggests that empathy is influenced by the relationship or attachment associated with 'the other' and is perceived as an in-group phenomenon.

Our data demonstrate the ability of sport fans to relate to the lifeworld of the athlete to experience and understand how or why they deal emotionally and cognitively with respect to particular transgressions. In articulating fan empathy, we capture what identifies it as a unique form of fan engagement with sport, including the aspects of the process and outcome of related sensemaking (Weick, 1995), and how this involves drawing on personal experience, information and inference to understand and explain athlete behavior. However, while we propose that the concept of fan empathy exists, we must make the point that depending on the context surrounding the transgression, an athlete's transgression may not always be met with an empathetic response. As presented in our findings however, an empathetic response was seen in the following instances: when transgressions were perceived to be less severe with no adverse effects to a third party; if transgressing athletes more generally had a favorable reputation; if the transgression was the result of circumstances perceived to be beyond an athlete's control; or in the case of minor transgressions that 
received heightened attention simply because the transgressor was an athlete. However, it was the fan's ability to place themselves in the lifeworld of the athlete that influenced their ability to empathize with that athlete's situation.

\subsection{Theoretical contribution}

Our research contributes to theory in several ways. First, it introduces the notion of fan empathy to the sport management literature and in doing so expands our understanding of fandom in terms of how sport is experienced and how the actions of sport's actors are understood. We highlight that empathizing as a result of an appreciation of key aspects of athletes' identity, capability or broader lifeworld on and off the field, can be a means by which fans engage deeply, both emotionally and cognitively. The capacity to experience empathy may lead to a more intense fan experience, providing further understanding of fan motivation to engage with sport.

Second, we add to the literature on team identification, specifically in relation to how fans relate to an athlete's lifeworld in a way that affords empathy and may enable them to maintain their capacity to identify even when events threaten that connection. Making sense of these incidents in a manner which results in an empathetic response allows fans to manage the conflict that arises when violations of values and norms are exposed that are at odds with the sport object (Hyatt \& Foster, 2015). The data examined here, particularly the online data, suggest that sensemaking strategies may reflect scripts that highly identified fans adopt in order to be apprenticed and habituated into their social reality. Empathy may even result from a sensemaking process in response to the sense-giving inputs provided by other identified fans (Fleming, 2001; Maitlis \& Lawrence, 2007).

Third, this research has linked the experience of fan empathy within an athlete transgressions context. We suggest that this connection has theoretical relevance because empathy may be amplified under conditions where either athlete or fan emotional responses 
are heightened. Previous studies on sport-related transgressions have revealed the impact of negative athlete behaviour on sport property stakeholders (Doyle, Pentecost \& Funk, 2014; Lee et al., 2015; Westberg et al., 2011) demonstrating the potential for adverse effects in the relationships between sport brands or athletes and their fans as well as sponsors or endorsed brands. Here, however-more in line with research from clinical psychology-fan empathy might lead to stronger fandom where higher emotional regulation facilitates greater levels of empathy (Hein, Röder, \& Fingerle, 2018). Furthermore, in some non-sporting circumstances, research has demonstrated that empathy after a transgressional act might stimulate an observer to take active and vigorous roles in the transgressor's defence (Breithaupt, 2018; Gutwald, 2018). Our contribution through introducing the fan empathy concept provides more texture to the understanding of athlete transgressions in sport and the nuanced, sometimes counterintuitive responses of fans. By implication, we note the effects of the 'sporting gaze' (Huggins, 2008) as a socially-acquired perspective of sport and its actors. The sporting gaze influences what sport fans expect to see. As the results from this study suggest, athlete transgressions may not be seen in the same way as transgressions occurring in other contexts, such as by politicians or actors. The use of empathy as a conceptual lens, therefore, suggests the pre-eminence of social context as sport fans probably react quite differently depending upon their levels of identification and attachment.

Fourth, this research offers some insight into the mechanisms of fan sensemaking. Fans are seldom considered as sensemaking agents in sport marketing studies, their personal fandom narratives often divorced from the critical embodied and emotional contexts in which they transpire (Cunliffe \& Coupland, 2011). Our results reinforce a view of fan sensemaking that occurs in the lived expressions of the everyday experience. Fans strive to smooth out multiple and contested personal narratives through an embodied process of cognitive interpretation where the senses, the body, emotions, and self-identifications cannot be 
separated. We suspect that the use of empathy reflects a more inclusive conceptual net to capture the embodied, personal narratives that sport fans employ in order to make sense of their fandom. Significant events like transgressions can have a constitutive influence upon fans' consumption, but it is not always easy to expose these enmeshed and fluid perceptions. We suggest that empathy offers a useful methodological tool to help explore the formative events that shape fans' responses.

Finally, given the nature of strong emotional experiences in sport, our work has added to the holistic approach needed to better appreciate fandom (Cottingham, 2012) and contributed to our understanding of the complex nature of what it means to be a passionate sport consumer. Specifically, the fan empathy concept helps to operationalise the connection between cognition and emotion concordant with the now well-accepted foundational principles developed in the cognitive sciences. For example, the somatic marker hypothesis explains how emotion seamlessly integrates with cognitive processes (Damasio, 1999). Just thinking about an action produces an emotional association, while the experience of an emotional sensation introduces thoughts relevant to the feelings; every thought involves an emotional element and vice-versa (Damasio 1999, Fazio 2001). With emotion prescient in the processing of team-related marketing stimuli (Kwak et. al., 2011), the understanding of empathy adds an important consideration that can extend beyond making sense of athlete (mis)behaviors and include the subsequent actions and decisions of team management themselves or the experience of athletes more generally. These are discussed in the managerial implications that follow.

\subsection{Managerial implications}

The ability to experience fan empathy has important implications for maintaining a fan's connection with a sport, team or athlete and is relevant to sport managers seeking to maintain fan loyalty. More broadly, empathy has been found to increase based on similarity, 
familiarity, social closeness and a positive experience with the other (de Waal, 2008; Preston and de Waal, 2002). Adding to this, our results demonstrate how empathy can also be a means by which identified fans maintain their connection when negative incidents occur, such as athlete transgressions, that might otherwise threaten that identity.

As technology brings fans closer to the action on the field and the media take fans closer to the action off the field, empathy is likely to become a more salient part of the sport experience. Our results have key implications for sport managers when designing strategies to enhance or maintain the identification, loyalty and experience of their fans. These results highlight that fans' understanding of the broader circumstances faced by athletes can facilitate empathy, allowing them to appreciate and make sense of the increasing scrutiny, conformity and rigidity faced by the modern elite sporting participant.

For sport managers, the realization that fans will seek to defend their favored teams when athletes transgress is not a new insight given the group-think behaviors and camaraderie embedded in fandom (Stavros, Meng, Westberg \& Farrelly, 2014). However, the approaches used by fans that lead to empathy, including drawing forth key elements of the athlete's lifeworld and how they may contribute to the issue, could be of critical significance in how sport managers (re)engage fans, and more particularly take steps to protect the sport brand from negative publicity and its consequences.

As sponsors, the media and other allied networks often take their cues from fan sentiment, the sport manager's ability to facilitate the knowledge or experiences needed for fans to gain insight into the lifeworld of an athlete is paramount. Recognizing the fan's capacity for empathy may also help individual athletes better navigate their own brand persona and how it is perceived by fans in a way that will allow them to empathize with a range of circumstances experiences. 
This opportunity for an empathetic response to emerge as a transgression unfolds is particularly relevant in instances where fans are willing to 'reserve judgment', seeking to allow initial impressions to unfold and reveal deeper insights that provide a context for their understanding. Providing information that may facilitate an empathetic response, such as athlete statements, interviews and evidence that counter balances negative media reports, is helpful for fans to make informed judgments that go beyond the reactionary. This information may also seek to shift the attention away from the incident and on to the handling of the process, evoking empathy for the circumstances that will undoubtedly garner more attention and insight into the fish-bowl existence of the modern athlete (Smith \& Stewart, 2010). The reserving of judgment closely aligns to the process of 'weighing the evidence' where fans seek to assess negative information against their own knowledge of the athlete or the context. Sport managers are pivotal in collating and curating this 'evidence' but must take care to ensure that it is seen as authentic.

The enhanced scrutiny of athletes is also evident in the process of 'moral testing' where normative standards are essentially benchmarked and where initial impressions may be tempered by simple comparative measures where the actions of an athlete or sporting organization are placed into some broader context. While athletes are often marketed as super-human, their frailties almost always match social and cultural norms, and this is readily highlighted. This humanizing element is increasingly captured by insider perspectives that make up both a large amount of social media content from athletes and their teams (and likely to be followed by highly-identified fans) as well as the move to greater 'reality' incursions into sporting life being sought by teams through various video streaming platforms as they seek to expand their branding (Bakare, 2018). Similarly, 'recognizing unfair expectations' can be undertaken in a comparative way, with sports managers within a league or sport 
encouraged to work collaboratively to ensure that fans have a nuanced understanding that goes beyond just their own affiliations.

Such new perspectives may also assist in the process of explaining a lack of control by better illuminating the pressures of athletes in their day-to-day activities, an area in which traditional media has limited access. As athletes build complex profiles on social media, the sport manager is better able to establish a base of information that can easily be accessed to highlight positive athlete behavior or ascribe circumstances that can be explanatory in nature. Seeing athletes 'behind the scenes' provides not only a stronger insight into the athlete's lifeworld by revealing the challenges in achieving success and the circumstances within which they must operate. Certainly, perceptions of privilege often associated with elite talent can be mitigated by the commensurate display of rigor required to reach such a level. New technologies also exist to highlight this, capturing the intricate detail of athlete performance through a range of embedded sensory devices that bring elements of high-performance to the forefront of fan viewing, allowing them to empathize through closer connection to the emotion, decision-making, and performance of elite athletes.

The results suggest that managers can play a pivotal role in engendering identification (Turner, Swart \& Maylor, 2012) and, in doing so, empathy. This sense-giving craftsmanship from sporting leaders can play a significant part in shaping fan responses to athlete behaviors (Peirano-Vejo \& Stablein, 2009). Acting as sense-giver (Dunford \& Jones, 2000), a sport organization's interpretation and contextualization of events can serve to construct a compelling message that assists in facilitating sensemaking that leads to an empathetic response from the identified fan. However, sport managers also need to be mindful of the wider audience for their messages and ensure that they are not perceived by key stakeholders or the broader community as attempting to trivialize or 'downplay' more serious transgressions. 


\subsection{Limitations and future research}

Despite the important contribution of this research, some limitations must be acknowledged. While the focus of this research was to explore the concept of fan empathy and how it is manifest, our results are specific to the context of athlete transgression and focus on informants from one geographical area.

Further research should explore other contexts in which fan empathy may be experienced, for example, poor team performance or the loss of key players and in different markets, including different sports. It may also be of value to consider whether fans can engage in empathy when watching sport, especially when they are close to the action (physically or through specialist technology that provides an immersive perspective such as virtual reality or haptic sensors) as this may prompt them to consider how the athlete processes emotion (such as fear) or makes decisions in the field of play and engage more deeply as a result.

In addition, while our study design allowed us to explore immediate response to athlete transgressions through the online dataset, our interview data relied on the recall of the informants in terms of their response to an earlier athlete transgression. Future research should seek to capture the immediate reactions to transgressions as well as consider how a fan's response may change over time, particularly the lifespan of the media attention and athlete or team response to a transgression. Additional research could also explore how the responses by athletes or team management can influence fan empathy and the context and circumstances in which transgressions are unlikely to engender an empathetic response from fans. While we were able to identify the different sense making processes that could lead to an empathetic response, it is not known whether a particular process may contribute more strongly to an empathetic response and whether different processes are more likely to be used for making sense of different types of transgressions. Further studies are also needed to 
explore the specific nature of the relationship between fan empathy and the extent to which it may influence a fan's ongoing support or identification of a sport entity.

Finally, the role of online fan forums in contributing to individual, or potentially a collective empathetic response to a transgression would provide a fruitful context for additional research. The data suggest that fan identification may be canalized through symbolic communication strategies that guide meaning-making. From this perspective, studying sense making processes that engender empathy offers greater insight into the covert constructions of high levels of identification. An outcome, as noted from the online data set, is that standards of social responses to transgressions are legitimized when they display an empathetic disposition. Legitimization helps to signal shared identification via systems of symbolic reference, in this case the language of an identified online participant. Future research could explore the dynamics of the sensemaking processes in an online context and how the collective interaction in the sensemaking process may, or may not, contribute to fan empathy. 


\section{References}

Aaker, J., Fournier, S., \& Brasel, A.S. (2004). When good brands do bad. Journal of Consumer Research, 31(1), 1-16.

Aggarwal, P., Castleberry, S.B., Ridnour, R. \& Shepherd, C.D. (2005). Salesperson empathy and listening: Impact on relationship outcomes. Journal of Marketing Theory \& Practice, 13(3), 16-31.

Argo, J., Zhu, R., \& Dahl, D. (2008). Fact or fiction: An investigation of empathy differences in response to emotional melodramatic entertainment. Journal of Consumer Research, 34, 614-623.

Ashworth, P., \& Lucas, U. (2000), Achieving empathy and engagement: A practical approach to the design, conduct and reporting of phenomenographic research. Studies in Higher Education, 25(3), p. 295-307.

Bakare, L. (2018). Juventus and All Blacks turn to TV shows to win fans: Retrieved from https://www.theguardian.com/football/2018/feb/19/juventus-and-all-blacks-turn-to-tvshows-to-win-fans.

Breithaupt, F. (2018). The bad things we do because of empathy. Interdisciplinary Science Reviews, 43(2), 166-174.

Breithaupt, F. (2012). A three-person model of empathy. Emotion Review, 4, 84-91. Branscombe, N.R., \& Wann, D.L. (1991). The positive social and self concept consequences of sport team identification. Journal of Sport and Social Issues, 15(2), 115-127.

Charmaz, K. (2014). Constructing grounded theory (2 $2^{\text {nd }}$ ed). UK: Sage

Corbin, J. (1998). Alternative interpretations: Valid or not? Theory \& Psychology, 8(1), 121-128.

Corbin, J., \& Strauss, A. (2008). Basics of qualitative research: Techniques and procedures for developing grounded theory (3rd ed.). Thousand Oaks, CA: Sage. 
Cottingham, M.D. (2012). Interaction ritual theory and sports fans: Emotion, symbols, and solidarity. Sociology of Sport Journal, 29, 168-185.

Cunliffe, A., \& Coupland, C. (2012). From hero to villain to hero: Making experience sensible through embodied narrative sensemaking. Human Relations, 65(1), 63-88.

Damasio, A. (1999). The Feeling of What Happens: Body and Emotion in the Making of Consciousness. New York: Harcourt.

Davis, C., Jiang, L., Williams, P., Drolet, A., \& Gibbs, B.J. (2017). Predisposing customers to be more satisfied by inducing empathy in them. Cornell Hospitality Quarterly, $58(3), 229-239$.

deWaal, F.B.M. (2008). Putting the altruism back into altruism: The evolution of empathy. Annual Review of Psychology, 59, 279-300.

Decety, J. \& Jackson, P.L. (2004). The functional architecture of human empathy. Behavioral and Cognitive Neuroscience Reviews, 3(2), 71-100.

Decety, J. \& Lamm, C. (2006). Empathy through the lens of social neuroscience, The Scientific World Journal, 6, 1146-1163.

Delia, E.B. (2015). The exclusiveness of group identity in celebrations of team success, Sport Management Review, 18(3), 396-406.

Doyle, J.P, Pentecost, R.D., \& Funk, D.C. (2014). The effect of familiarity on associated sponsor and event brand attitudes following negative celebrity endorser publicity. Sport Management Review, 17, 310-323.

Duan, C. \& Hill, C.E. (1996). The current state of empathy research. Journal of Counselling Psychology, 43, 261-274.

Dunford, R. \& Jones, D. (2000). Narrative in strategic change. Human Relations, 53, 1207-1226. 
Eisenberg, N. (2000). Emotion, regulation, and moral development. Annual Review of Psychology, 51, 665-697.

Escalas, J.E. \& Stern, B.B. (2003). Sympathy and empathy: Emotional responses to advertising dramas. Journal of Consumer Research, 29(4), 566-578.

Fleming, D. (2001). Narrative leadership: Using the power of stories. Strategy \& Leadership, 29, 34-36.

Fazio, R.H. (2001). On the automatic activation of associated evaluations: An overview. Cognition and Emotion, 15, 115-141.

Fink, J.S., Parker, H.M., Brett, M., \& Higgins, J. (2009). Off-field behavior of athletes and team identification: Using social identity theory and balance theory to explain fan reactions. Journal of Sport Management, 23, 142-155.

Fisher, R.J. \& Wakefield, K. (1998). Factors leading to group identification: A field study of winners and losers. Psychology and Marketing, 15(1), 23-39.

Funk, D. \& James, J. (2006). Consumer loyalty: The meaning of attachment in the development of sport team allegiance. Journal of Sport Management, 20(2), 189-217.

Funk, D. \& Pritchard, M. (2006). Sport publicity: Commitment's moderation of message effects. Journal of Business Research, 59(5), 613-621.

Gerdes, K. \& Segal, E. (2011). Importance of empathy for social work practice: Integrating new science, Social Work, 56(2), 141-147.

Gutwald, R. (2018). Why people do what others do: And why that is sometimes good and sometimes bad. Journal of Human Development and Capabilities, 19(1), 97-102.

Hattula, J.D., Herzog, W., Dahl, D.W., \& Reineke, S. (2015). Managerial empathy facilitates egocentric predictions of consumer empathy. Journal of Marketing Research, 52, 235-252. 
Hein, S., Röder, M., \& Fingerle, M. (2018). The role of emotion regulation in situational empathy-related responding and prosocial behaviour in the presence of negative affect. International Journal of Psychology, 53(6), 477-485.

Huggins, M. (2008). The sporting gaze: Towards a visual turn in sports history documenting sport and art. Journal of Sport History, 25(2), 311- 329.

Hyatt, C.G., \& Foster, W.M. (2015). Using identity work theory to understand the deescalation of fandom: a study of former fans of National Hockey League teams. Journal of Sport Management, 29(4), 443-460.

Kim. Y.K., \& Trail, G. (2011). A conceptual framework for understanding relationships between sport consumers and sport organizations: a relationship quality approach. Journal of Sport Management, 25(1), 57-69.

Kozinets, R.V. (2010). Netnography. Doing ethnographic research online, Los Angeles: Sage.

King, J., Kahle, L.R., \& Close, A. (2011). The study of sports and events consumer behavior, In Kahle, L.R. and A. Close (Eds.), Consumer behavior knowledge for effective sports and event marketing (pp. 1-28). New York: Routledge.

Krebs, D.L. (1970). Altruism: An examination of the concept and a review of the literature. Psychological Bulletin, 73, 258-302.

Kwak, D.H., Kim, Y.K., \& Hirt, E.R. (2011). Exploring the role of emotions on sport consumers' behavioral and cognitive responses to marketing stimuli. European Sport Management Quarterly, 11(3), 225-250.

Lee, J.S., \& Kwak, D.H. (2017). Can winning take care of everything? A longitudinal assessment of post-transgression actions in repairing trust in an athlete endorser. Sport Management Review, 20, 261-272. 
Lee, J.S., Kwak, D.H., \& Braunstein-Minkove, J.R. (2016). Coping with athletes' immoral behavior: Roles of athlete identification and moral emotions on moral reasoning strategies. Journal of Sport Management, 30(2), 176-191.

Lee, J. S., Kwak, D. H., \& Moore, D. (2015). Athletes' transgressions and sponsor evaluations: A focus on consumers' moral reasoning strategies. Journal of Sport Management, 29(6), 672-687.

Mael, F. \& Ashforth, B. (1992). Organizational identification: Construct redefinition and a field application with organizational alumni. Journal of Organizational Behavior, 13, 103-123.

Maitlis, S. \& Lawrence, T. B. (2007). Triggers and enablers of sensegiving in organizations. Academy of Management Journal, 50, 57-84.

Misch, D.A. \& Peloquin, S.M. (2005). Developing empathy though confluent education. Journal of Physiotherapy Education, 19(3), 41-51.

Mutter, F., \& Pawlowski, T. (2014). Role models in sports - Can success in professional sports increase the demand for amateur sport participation? Sport Management Review, 17(3), 324-336.

Parry K.D. (2009). Search for the hero: An investigation into the sports heroes of British sports fans. Sport in Society: Cultures, Commerce, Media, Politics, 12(2), 212-226.

Peirano-Vejo, M. E. \& Stablein, R. E. (2009). Constituting change and stability: Sensemaking stories in a farming organization. Organization, 16, 443-462.

Pizarro, D. (2000). Nothing more than feelings? The role of emotions in moral judgment. Journal for the Theory of Social Behaviour, 30(4), 355-375.

Preston, S.D. \& de Waal, F.B.M. (2002). Empathy: Its ultimate and proximate bases. Behavioral and Brain Sciences, 25, 1-72. 
Rojek, C. (2006). Sports celebrity and the civilizing process. Sport in Society: Cultures, Commerce, Media, Politics, 9(4), 674-690.

Romani, S., Grappi, S., Zarantonello, L., \& Bagozzi, R.P. (2015). The revenge of the consumer! How brand violations lead to consumer anti-brand activism. Journal of Brand Management, 22(8), 658-672.

Sato, S., Ko, Y. J., Park, C., \& Tao, W. (2015). Athlete reputational crisis and consumer evaluation. European Sport Management Quarterly, 15(4), 434-453.

Segal, E.A. (2011). Social empathy: A model built on empathy, contextual understanding, and social responsibility that promotes social justice. Journal of Social Service Research, 37(3), 266-277.

Singer, T. \& Lamm, C. (2009). The social neuroscience of empathy, The Year in Cognitive Neuroscience 2009, New York Academy of Sciences, 81-96.

Smith, A.C.T. \& Stewart, B. (2010). The special features of sport: A critical revisit. Sport Management Review, 13, 1-13.

Stavros, C., Meng, M. Westberg, K. \& Farrelly, F. (2014). Understanding Fan Motivation for Interacting on Social Media, Sport Management Review, 17, 455-469.

Strauss, A., \& Corbin, J. (1990). Basics of qualitative research: Grounded theory procedures and techniques. Newbury Park, CA: Sage.

Sturmer, S., Snyder, M., Kropp, A., \& Siem, B. (2006). Empathy-motivated helping: The moderating role of group membership. Personality and Social Psychology Bulletin, 32(7), 943-956.

Sutton, W.A., McDonald, M.A., \& Milne, G.R. (1997). Creating and fostering identification in professional sports. Sport Marketing Quarterly, 6(1), 15-22.

Tangney, J.P., Stuewig, J. \& Mashek (2007). Moral emotions and moral behavior, Annual Review of Psychology, 58, 345-372. 
Turner, N., Swart, J. \& Maylor, H. (2012). Mechanisms for managing ambidexterity: A review and research agenda. International Journal of Management Reviews, 15, 317-332.

Wann, D.L. (2006). The causes and consequences of sport team identification. In A.A. Raney \& J. Bryant (Eds.), Handbook of sport and media (pp. 331-352). Mahwah, NJ: Lawrence Erlbaum.

Wann, D.L. \& Dolan, T.J. (2001). Attributions of highly identified sport spectators. The Journal of Social Psychology, 134(6), 783-792.

Weick, K.E. (1995). Sensemaking in organizations, Thousand Oaks, CA: Sage Publications.

Weißhaar, I. \& Huber, F. (2016). Empathetic relationships in professional services and the moderating role of relationship age. Psychology \& Marketing, 33(7), 525-541.

Westberg, K., Stavros, C., \& Wilson, B. (2011). The impact of degenerative episodes on the sponsorship B2B relationship: Implications for brand management. Industrial Marketing Management, 40(4), 603-611.

Zhao, J., Abrahamson, K., Anderson, J., Ha, S., \& Widdows, R. (2013). Trust, empathy, social identity, and contribution of knowledge within patient online communities. Behavior and Information Technology, 32(10), 1041-1048.

Zuwerink Jacks, J. \& Cameron, K.A. (2003). Strategies for resisting persuasion. Basic and Applied Social Psychology, 25(2), 145-161. 
TABLE 1: Informant Details

\begin{tabular}{lll}
\hline Pseudonym & Age & \multicolumn{1}{c}{ Family Status } \\
\hline $\begin{array}{l}\text { Male: } \\
\text { Ian }\end{array}$ & 50 & $\begin{array}{l}\text { Married, 1 older child } \\
\text { David }\end{array}$ \\
Mark & 33 & Single, no children \\
Daniel & 30 & Married, 2 young children \\
Sean & 28 & Married, 2 young children \\
Marcus & 30 & Single, no children \\
Sam & 36 & Married, 1 young child \\
Female: & & \\
Bianca & 35 & Single, no children \\
Natalie & 43 & Married, 1 young child \\
Jessica & 37 & Married, 3 older children \\
Kim & 45 & Married, 2 older children \\
Sylvia & 39 & Married, 2 young children \\
Claire & 32 & Married, 2 young children \\
Bernadette & 37 & Married, 3 young children \\
Lydia & 33 & Married, 2 young children \\
\hline
\end{tabular}

